\title{
Estimating the Economic Value of Improving the Asian Dust Aerosol Model in the Korean Household Sector: A Choice Experiment
}

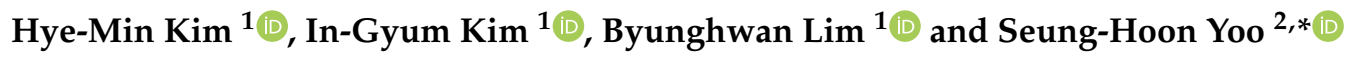 \\ 1 Planning and Finance Division, National Institute of Meteorological Sciences, 33 Seohobuk-Ro, Seogwipo, \\ Jeju 63568, Korea; hmkim84@korea.kr (H.-M.K.); kimig@korea.kr (I.-G.K.); weatherman@korea.kr (B.L.) \\ 2 Department of Energy Policy, Graduate School of Energy \& Environment, Seoul National University of \\ Science \& Technology, 232 Gongreung-Ro, Nowon-Gu, Seoul 01811, Korea \\ * Correspondence: shyoo@seoultech.ac.kr; Tel.: +82-2-970-6802
}

check for updates

Citation: Kim, H.-M.; Kim, I.-G.; Lim, B.; Yoo, S.-H. Estimating the Economic Value of Improving the Asian Dust Aerosol Model in the Korean Household Sector: A Choice Experiment. Sustainability 2021, 13, 12054. https://doi.org/10.3390/ su132112054

Academic Editors: Andy Chan and $\mathrm{Li} \mathrm{Li}$

Received: 27 September 2021

Accepted: 28 October 2021

Published: 1 November 2021

Publisher's Note: MDPI stays neutral with regard to jurisdictional claims in published maps and institutional affiliations.

Copyright: (c) 2021 by the authors. Licensee MDPI, Basel, Switzerland. This article is an open access article distributed under the terms and conditions of the Creative Commons Attribution (CC BY) license (https:/ / creativecommons.org/licenses/by/ $4.0 /)$.

\begin{abstract}
Asian dust (AD), a seasonal phenomenon in East Asia, refers to dust winds that blow from inland China and the Gobi Desert. Generally, AD occurs in the spring, but due to climate change and the desertification of AD sources, it has recently started occurring in every season except for midsummer. The occurrence of AD adversely affects human health and damages various industries. Accordingly, the Korean Meteorological Administration has provided an AD forecast service to minimize damage. The most essential part of providing the AD forecast service is the Asian Dust Aerosol Model (ADAM). This study tries to provide useful information for policymaking and research and development by deriving the economic value of ADAM improvement. To this end, a choice experiment (CE) was applied. The CE can derive the marginal value of or the marginal willingness to pay (MWTP) of improvement in attribute. All the MWTP estimates obtained in this study were statistically significant. The household MWTP estimates for a 1\% improvement in ADAM accuracy and a one-level subdividing were obtained as USD 0.04 and USD 0.12 per household. This finding indicates that people have a greater preference for improving AD forecast segmentation than for improving ADAM accuracy.
\end{abstract}

Keywords: Asian Dust Aerosol Model; economic value; choice experiment; marginal willingness to pay

\section{Introduction}

Every spring, sand dust from the Chinese inland area and the Gobi Desert has a significant impact on human health, air quality, and several industrial sectors [1-8] especially in eastern China, but also in Korea, Japan, and even North America. This sand dust is called "Asian dust (AD)". Originally, AD was a seasonal weather phenomenon occurring mainly in the spring. However, because of desertification in China and Mongolia, AD now occurs every season except for the summer. The AD concentration level is getting higher and when AD occurs, maintained dates are becoming longer [9]. The study of AD's influence on various health effects, including even mortality and suicide [1-4], has been undertaken.

AD's effect on elderly residents' (aged 65 years and older) cause-specific mortality in Seoul (South Korea), Nagasaki, Matsue, Osaka, and Tokyo (Japan) was evaluated to find that a high concentration of AD elevates the pooled risk of all-causes mortality and cerebrovascular disease in four cities except Tokyo [1]. Moreover, the paper that estimated the pooled effects of AD storms revealed that there is a significant positive correlation between AD storms and mortality, and that AD affects the rates of death, cardiovascular health, and respiratory health of persons aged 65 years and older in South Korea [2,3]. AD influences not only human life but also global warming. It worsens global warming by reflecting or absorbing sunlight [10]. 
A few studies have been published enumerating the positive effects of AD. One study found inorganic nutrients and microelements included in AD and found that it has a beneficial influence on phytoplankton growth in oceans [11]. Another study identified differences in soil potential hydrogen $(\mathrm{pH})$ levels between the AD source area and the Korean peninsula. The soil $\mathrm{pH}$ level in the AD source area has been measured as higher than in the Korean peninsula, which implies that AD helps prevent soil acidification in Korea [12]. However, recent studies have revealed that AD contains heavy metals and 10-micrometer particulate matter $\left(\mathrm{PM}_{10}\right)$, which is harmful to the human body [13]. For that reason, people have recently been paying more attention to AD forecasts and alerts.

The Korean Meteorological Administration (KMA) provides AD information and alerts to the public when AD occurs or is expected to occur to minimize its damage. To produce AD forecasts, the KMA monitors the AD source area, observes AD conditionswhich include temperature-vegetation dryness, ascending air currents, ground wind speed, AD ground concentration level, and AD paths-and analyzes the possibility of AD inflow to the Korean peninsula. The Asian Dust Aerosol Model (ADAM) is used to estimate the path of AD, the possibility of AD inflow to the Korean peninsula, the end of an AD event, the possibility of re-inflow, and other relevant metrics. The AD forecasting service supplies information about the time and region of AD occurrences as well as the incidence of AD. The KMA provides $72 \mathrm{~h}$ of AD-event forecast information, and AD alerts take effect when an $\mathrm{AD}$ event is expected to be maintained above 800 milligrams $(\mathrm{mg})$ per cubic meter $\left(\mathrm{m}^{3}\right)$ for more than two hours. This service is expected to be used not only by the elderly and infirm but also by many industries.

An improvement in the AD forecasting service must be preceded by an improvement in ADAM. The prime purpose of this paper is, therefore, to value ADAM improvement. The valuation will be tried for Korean households. This research seeks to utilize a choice experiment (CE), a frequently applied technique for valuing a non-market good [14-19]. The value of each attribute is estimated by analyzing the respondents' marginal willingness to pay (MWTP) for a unit of change in the attributes related to improving ADAM.

The rest of this article is structured in the following manner. Section 2 explores some previous studies that have applied the CE employed in this research. The overall procedures and methodology for conducting this research are described in Section 3. More specifically, the CE, the attributes and their levels, and the questionnaire are explained in the section. Section 4 is devoted to reporting the results and discussion. Conclusions are reported in the last section.

\section{Short Literature Review}

The contingent valuation (CV) and CE are widely used methods to value environmental and non-market goods. When we estimate the economic value of one attribute, $\mathrm{CV}$ can be utilized. CE is often adopted to value a good or service composed of multiple attributes. Before proceeding with this study, the authors examined some previous research that evaluated the economic value of improving a meteorological service or air quality using CE or CV. This is because the AD forecasting service is a meteorological service, and the occurrence of AD affects air quality.

Lee [17] evaluated AD cost in Korea using CE. The mean MWTP estimates per household per annum to reduce the frequency of AD for one day and to lower the concentration of particulates by $100 \mu \mathrm{g} / \mathrm{m}^{3}$ were USD 0.75 and USD 0.67 , respectively. Tesfaye et al. [18] investigated the WTP of receiving climate services through an interactive voice-response system in Ethiopia with using CE. Respondents preferred the voice-response system (VRS) over a text-response system. WTPs derived by VRS and text-response system were USD 1.34 and USD 0.5, respectively. Nguyen et al. [19] analyzed the economic benefits ensuing from improving a tropical cyclone warning service through CE. In cyclone warning services, the economic value of the maximal improvement in the number of service attribute was USD 7.1 to 8.1 per household. Lin et al. [20] computed the economic value arising from the 
public meteorological services and found that the annual adjusted WTP for public meteorological information services ranged from USD 56.06 to 90.92 per agricultural household.

Lee et al. [21] measured the value that the Korean public place on a pollen forecast system. USD $0.133,-0.017,0.098,0.059$, and 0.011 were obtained as the monthly values of the pollen forecasting system's accuracy, interval, area, period, and information type. Park et al. [22] employed CV to assess the public value that Korean people put on the national meteorological service. The mean additional WTP for meteorological services per household was computed as USD 0.75 per month. Desaigues et al. [23] utilized CV to obtain the economic value of mortality caused by air pollution using a concept of the value of a life year (VOLY). From a nine-country CV survey, the VOLY was estimated at EUR 40,000 for a cost-benefit analysis of air pollution policies for the European Union. Donfouet et al. [24] evaluated a monthly USD 0.42 per household of improved air quality in urban Africa using a CV survey. Table 1 shows the previous studies reviewed in this study.

Table 1. Findings from previous studies on meteorological services and air quality.

\begin{tabular}{|c|c|c|c|}
\hline Country and Sources & Methods & Attributes & Results \\
\hline \multirow{4}{*}{ South Korea [17] } & \multirow{3}{*}{ CE } & Asian dust & \\
\hline & & Reducing the frequency for 1 day & USD 0.75 per year \\
\hline & & $\begin{array}{l}\text { Reducing the level of particulates by } 100 \\
\text { micrograms per cubic meter }\left(\mu \mathrm{g} / \mathrm{m}^{3}\right)\end{array}$ & USD 0.67 per year \\
\hline & \multirow{3}{*}{ CE } & Receiving system of climate services & \\
\hline \multirow[t]{2}{*}{ Ethiopia [18] } & & $\overline{\text { An interactive voice-response system }}$ & USD 1.34 \\
\hline & & An interactive text-response system & USD 0.5 \\
\hline Vietnam [19] & CE & Cyclone warning services & USD 7.1 to 8.1 \\
\hline \multirow[t]{2}{*}{ Taiwan [20] } & \multirow[t]{2}{*}{$\mathrm{CV}$} & $\frac{\text { Meteorological information services }}{\text { for agriculture }}$ & \multirow[t]{2}{*}{ USD 56.06 to 90.92 per year } \\
\hline & & Pollen forecasting system & \\
\hline \multirow{5}{*}{ South Korea [21] } & \multirow{5}{*}{$\mathrm{CE}$} & $\overline{\text { Accuracy }}$ & USD 0.133 per month \\
\hline & & Interval & USD - 0.017 per month \\
\hline & & Area & USD 0.098 per month \\
\hline & & Period & USD 0.059 per month \\
\hline & & Information type & USD 0.011 per month \\
\hline South Korea [22] & $\mathrm{CV}$ & Meteorological services & USD 0.75 per month \\
\hline EU (nine countries) [23] & $\mathrm{CV}$ & Air pollution & EUR 40,000 \\
\hline Cameroon [24] & $\mathrm{CV}$ & $\overline{\text { Air quality }}$ & USD 0.42 per month \\
\hline
\end{tabular}

Note: CV means contingent valuation and CE implies choice experiment.

\section{Methodologies}

\subsection{Method for Valuing the Improvement of ADAM}

Conjoint analytical methods, including CE, were developed by Louviere et al. [25] and have been frequently applied in the fields of marketing, transportation, and psychology. Since CE was first applied to valuing a non-market good by Adamowicz [26], it has been used in various fields. The random utility maximization model is the theoretical basis of the $\mathrm{CE}$ approach. The model suggests that the utility of an individually chosen alternative is always bigger than the other alternatives not chosen. For this reason, this approach requires a survey of people who might be affected by research and development on ADAM.

The CE approach is one of the ways to estimate the relative values of the multiple attributes of a product. In particular, the approach can be ideally applied to an environmental and non-market good or a new product that is not yet available on the market $[18,27-31]$. Even if a good is not traded in the market, this technique can be usefully utilized when the valuation of the good is essential for policy purposes. Moreover, most experts positively evaluated results from applying CE. [32-37]. Therefore, using the CE approach is appropriate for effectively assessing public preferences for improving ADAM.

The CE approach is based on a survey and estimates the economic value of a good or service using respondents' preferences for several attributes. In the survey, various 
alternatives, such as baseline states and price attributes, also included were suggested to respondents. Subsequently, every interviewee was asked to select the best one of several alternatives from a personal standpoint. By analyzing the data from the respondents' choices, the results regarding the MWTP for each attribute can be obtained, as well as information about increasing or decreasing its level [15,38].

\subsection{Selection of Attributes}

The first task in applying CE is to carefully identify the attributes of the good to be evaluated. The identified attributes should have both relevance and understandability to the respondents. In addition, they should be of interest to them. For the purposes of identifying the attributes related to ADAM and determining their levels, the authors first made a preliminary list of attributes through a literature review and interviews with experts. In some of previous studies that valued some meteorological services, the variables including 'accuracy,' 'period,' and 'interval and others' had been usually selected as attributes. In this study, the authors focused on the services that can actually be provided after ADAM development and respondents' interest. There were several meetings with experts who were involved with ADAM development before the authors decided the attributes for this research. According to their comments, the subdivision of the forecast stage was accepted for reasons of practicality rather than the 'period' and 'interval' element because they are not possible to realize with developing ADAM by itself. As a result of that, we categorized attributes of ADAM as the level of forecast stage and accuracy.

The first attribute is a subdivision of the forecast stage. AD forecasting in South Korea is currently classified into four stages, which include "very bad (warning)", "bad (advisory)", "a little bit bad (alarm)", and "normal". According to the KMA, a "warning" is issued when the concentration of dust is expected to be larger than $800 \mu \mathrm{g} / \mathrm{m}^{3}$ per hour on average. In addition, $400-799 \mu \mathrm{g} / \mathrm{m}^{3}$ is applied to "bad", and $200-399 \mu \mathrm{g} / \mathrm{m}^{3}$ is considered "a little bit bad". The authors assume that more detailed classification stages provide more effective information for users.

The second attribute is the accuracy improvement rate of the AD forecast. This means the respondents felt that there was a distinction between the accuracy of an AD forecast at this point and their expectation of its accuracy. Here, $0 \%, 10 \%$, and 30\% accuracy improvement rates were considered. It would be natural for people to prefer better prediction accuracy than to stay at the current level of that.

The final attribute selected is the price, which indicates the amount of people's willingness to pay (WTP) for improving ADAM. In CE, this price attribute is also called the payment vehicle. The payment vehicle should not be unfamiliar to people, as they help overcome the hypothetical situation required in CE questions. In addition, the payment vehicle should have a clear connection with improving AD. In other words, improving ADAM might give respondents a chance to avoid AD damage.

There are 45 possible alternatives created from Table 2 . However, considering respondents' bounded rationality, time, and cost constraints, presenting all of these possible alternatives is not necessary or appropriate. The authors chose 16 alternatives with maineffects in an orthogonal design with the help of a statistical package (SPSS 12.0). The design method has been used to randomly mix and split to eight sets of two options each. Every respondent would be assigned randomly to one of the two groups. There were three alternatives in one choice set-that is, a choice set includes a business-as-usual alternative and two other comparable alternatives. Every interviewee was faced with four choice sets. Thus, all the respondents made four choices. An illustration of a choice set utilized in the CE survey is given in Figure 1. 
Table 2. Explanation of three attributes adopted in this research.

\begin{tabular}{|c|c|c|}
\hline Attributes & Description & Level \\
\hline Subdivision & The number of forecasting classification stages & $\begin{array}{l}\text { Level 1: } 4 \text { stages }^{\text {a }} \\
\text { Level 2: } 5 \text { stages } \\
\text { Level 3: } 7 \text { stages }\end{array}$ \\
\hline Accuracy & $\begin{array}{l}\text { The accuracy improvement rate of the } \\
\text { AD forecast }\end{array}$ & $\begin{array}{l}\text { Level 1: } 0^{\text {a }} \\
\text { Level 2: } 10 \% \\
\text { Level 3: } 30 \%\end{array}$ \\
\hline Price & $\begin{array}{l}\text { The willingness to pay for developing an AD } \\
\text { forecast by increasing the annual income tax } \\
\text { (units: Korean won (KRW)) }\end{array}$ & $\begin{array}{c}\text { Level 1: } 0^{\mathrm{a}} \\
\text { Level 2: } 500 \\
\text { Level 3: } 1500 \\
\text { Level 4: } 3000 \\
\text { Level 5: } 5000\end{array}$ \\
\hline
\end{tabular}

\begin{tabular}{|c|}
\hline $\begin{array}{c}\text { The number of } \\
\text { forecasting } \\
\text { classification stages of } \\
\text { ADAM }\end{array}$ \\
The accuracy \\
improvement rate of \\
ADAM \\
Additional annual \\
income tax for \\
improved ADAM \\
\hline $\begin{array}{c}\text { Check with } V \text { the } \\
\text { only available } \\
\text { altemative which you } \\
\text { prefer among } \\
\text { Alternative A, B or } \\
\text { status Quo }\end{array}$ \\
\hline
\end{tabular}

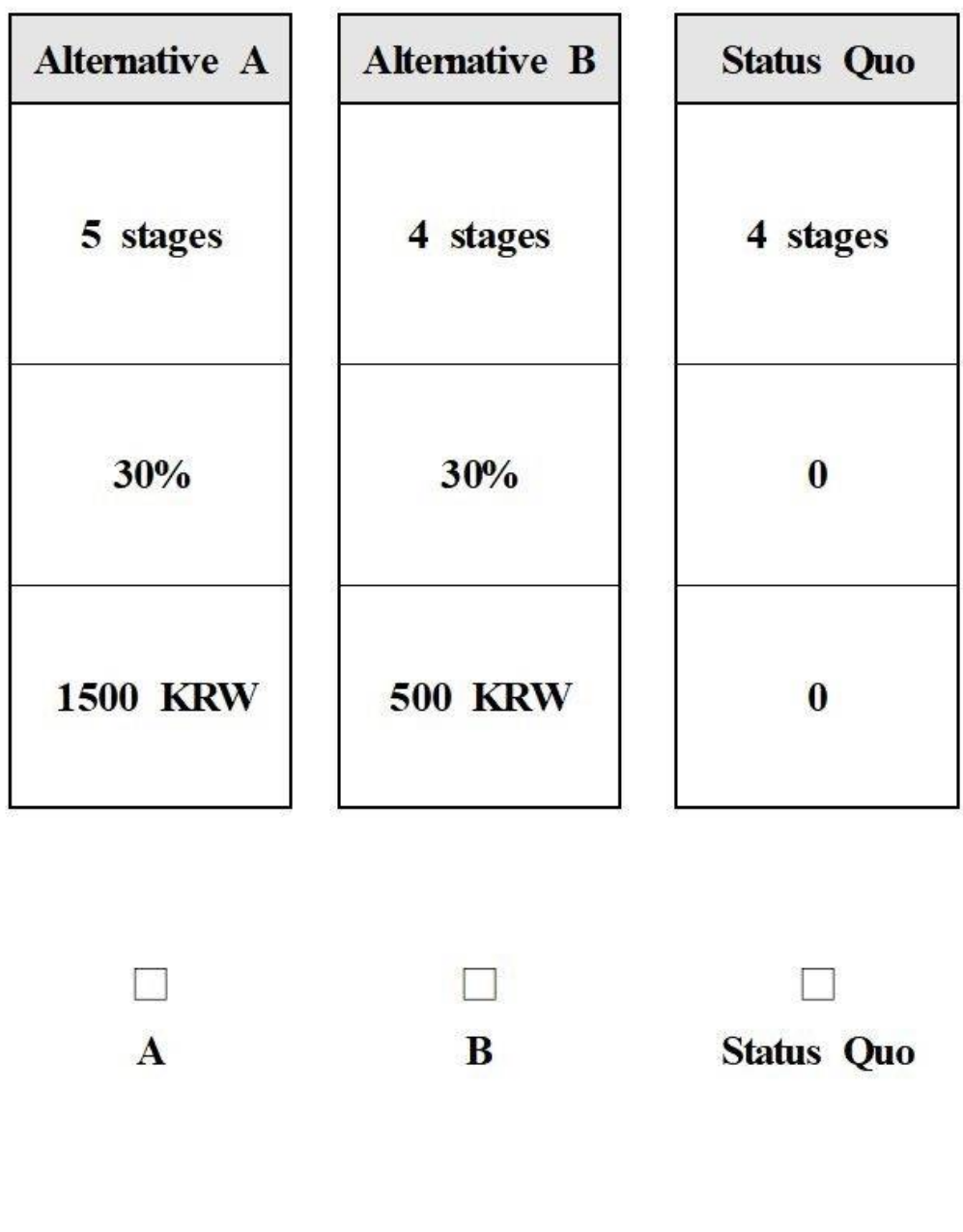

Figure 1. A sample choice set used in the survey.

\subsection{Survey Instruments and Methods}

The survey consisted of three steps. Some questions about ADAM comprised the first step. The purpose of the questions was to gather information on respondents' perceptions of ADAM. For the sake of supporting the respondents' better understanding the survey, a description of the AD prediction process with ADAM and the damages caused by AD was provided with color illustrations in this step. This step helps to reduce the respondents' burden-related value judgements and immerses them into the main part of the survey. 
The second step, the main part for the CE survey, contains explanations of attributes and questions concerning value judgments required in $\mathrm{CE}$ work.

A qualified polling firm with experience in CE survey interviews managed a nationwide survey (except for Jeju Province) of 1000 randomly chosen interviewees who were interviewed in person during November 2019. We would obtain four observations for each household, totaling a dataset of $4000(4 \times 1000)$. Householders or housewives over 20-65 years of age responded to the survey questions. Table 3 presents the respondents sample statistics including definitions. Before implementing the main survey, 30 people were asked to take the survey to improve the respondents' understanding of an initial version of the survey questionnaire.

Table 3. Explanation of respondents' socio-economic variables used.

\begin{tabular}{cccc}
\hline Variables & Definition & Mean & Standard Deviation \\
\hline Education & $\begin{array}{c}\text { Education level of the interviewee } \\
\text { in years }\end{array}$ & 13.62 & 2.04 \\
Income & $\begin{array}{c}\text { Monthly income of the interviewee } \\
\text { household (unit: million KRW }) \\
\text { Gender of the interviewee } \\
(1=\text { male, } 2=\text { female })\end{array}$ & 4.82 & 1.96 \\
\hline
\end{tabular}

\subsection{Utility Function}

Adopting the usual practice in the literature, it is assumed that the utility function has a linear form. Each level of Subdivision, Accuracy, and Price is denoted as $Y_{t}$ for $t=\mathrm{s}$, a, and p, respectively. Furthermore, an alternative-specific constant (ASC) is considered as an additional variable affecting the utility. The variable plays a role in capturing the influence of other factors not included in the utility function [28,39]. The ASC is defined as a dummy for the interviewee's selecting the business-as-usual alternative among three alternatives in a choice set. In other words, the ASC variable has a value of 0 or 1 . The utility that interviewee $j$ enjoys by choosing the alternative $m$ can be formulated as:

$$
U_{j m}=V_{j m}+\varepsilon_{j m}=\beta^{\prime} Y_{j m}+\varepsilon_{j m}=A S C_{j}+\beta_{s} Y_{s, j m}+\beta_{a} Y_{a, j m}+\beta_{p} Y_{p, j m}+\varepsilon_{j m}
$$

The WTP for one level increased of the attribute implies the MWTP. According to Roy's identity, given in microeconomic theory, the MWTP for an increase in the level of a specific attribute can be derived from Equation (1) as:

$$
M W T P_{X_{t}}=-\frac{\frac{\partial U}{\partial Y_{t}}}{\frac{\partial U}{\partial Y_{p}}}=-\frac{\beta_{t}}{\beta_{p}} \text { for } t=s, a
$$

\subsection{Model to Obtain the Utility Function}

Using basic statistics, the probability that interviewee $j$ enjoys by choosing alternative $m$ is expressed as:

$$
\begin{gathered}
P_{j m}=\operatorname{Pr}\left(U_{j m}>U_{j l}, \forall l \neq p\right) \\
=\operatorname{Pr}\left(V_{j m}+\varepsilon_{j m}>V_{j l}+\varepsilon_{j l}, \forall l \neq p\right) \\
=\operatorname{Pr}\left(\varepsilon_{j l}-\varepsilon_{j m}<V_{j m}-V_{j l}, \forall l \neq p\right) \\
=\int_{\varepsilon} D\left(\varepsilon_{j l}-\varepsilon_{j m}<V_{j m}-V_{j l}, \forall l \neq p\right) h\left(\varepsilon_{j}\right) d \varepsilon_{j}
\end{gathered}
$$

where $D()$ is an indicator function. That is, the function returns one if the argument is true but zero otherwise.

The most-usually used model for obtaining the utility function is the multinomial logit model. However, the model has two serious shortcomings. First, the model assumes 
independence from irrelevant alternatives (IIA). Second, the model does not reflect the preference heterogeneity. These two points are known to be quite restrictive in the literature. As an alternative to the model, this research seeks to apply the mixed logit (ML) model. The ML model does not suffer from the two shortcomings. In the model, the probability that interviewee $j$ enjoys by choosing alternative $m$ takes the form of:

$$
P_{j m}=\int \frac{\exp \left(\beta^{\prime} Y_{j m}\right)}{\sum_{l} \exp \left(\beta Y_{j l}\right)} k(\beta) d \beta
$$

It is quite complicated and too burdensome to directly handle Equation (4) with a classical method such as maximum likelihood estimation method. Thus, the authors try to employ a Bayesian approach to deal with Equation (4). Train [39] suggested the Bayesian approach based on Gibbs sampling and data augmentation. See Train [39] for more detailed explanation of the Bayesian approach.

\section{Results and Discussion}

\subsection{Data}

In conducting field surveys for estimating the economic value of a service or good by the CE method, a few points have to be focused on. First, the characteristics of the population should be reflected in a scientific sampling. Second, interviews should be conducted by experienced professional interviewers to acquire reliable responses. The authors entrusted the entire process of the survey to a professional survey company to concentrate on these two points. The survey was carried out for one month, November 2019, in all regions of Korea except Jeju province. According to interviewers belonging to the company, the survey was successfully conducted without any problems. Notably, the fact that the public's concern with air quality has increased in recent years seems to have helped respondents concentrate on this survey that related to Asian dust, which greatly affects air quality. In addition, $82.6 \%$ of interviewees answered that they experienced damages from $\mathrm{AD}$ in health, livelihood, or economy.

\subsection{Estimation Results}

The ML model should assume the specific distributional form of $\beta_{j}$. This enables it to tackle the heterogeneity of the respondents' preferences explicitly. At the first stage of the analysis, this study assumes that all the parameters are normally distributed. However, the coefficient estimate for the Subdivision variable had a negative sign with a normal distribution, unlike preliminary expectations. In addition, the coefficient estimate for the Accuracy variable did not secure statistical significance. Accordingly, the distribution of the parameters for the two attributes-Subdivision and Accuracy-were assumed to be log-normal instead of normal.

Table 4 reports the estimation results of two versions of the model. The table contains information on the mean and variance of the coefficient estimates. The second column of the table is related to the first basic model. The third column of the table is concerned with the model with covariates. The covariates refer to three variables regarding the respondents' characteristics as explained in Table 3. In other words, the respondents' education levels in years (Education), monthly household incomes (Income), and the respondents' genders (Gender) are used to allow for their impacts on the probability of selection. The model with covariates reflects these three variables. 
Table 4. Estimation results of two mixed logit models.

\begin{tabular}{|c|c|c|c|c|c|c|}
\hline \multirow[b]{2}{*}{ Variables $^{\text {a }}$} & \multicolumn{3}{|c|}{ Basic Model } & \multicolumn{3}{|c|}{ Model with Covariates } \\
\hline & $\begin{array}{c}\text { Assumed } \\
\text { Distribution }\end{array}$ & $\begin{array}{l}\text { Mean of the } \\
\text { Coefficient } \\
\text { Estimate }\end{array}$ & $\begin{array}{l}\text { Variance of the } \\
\text { Coefficient } \\
\text { Estimate }\end{array}$ & $\begin{array}{c}\text { Assumed } \\
\text { Distribution }\end{array}$ & $\begin{array}{l}\text { Mean of the } \\
\text { Coefficient } \\
\text { Estimate }\end{array}$ & $\begin{array}{c}\text { Variance of the } \\
\text { Coefficient } \\
\text { Estimate }\end{array}$ \\
\hline $\mathrm{ASC}^{\mathrm{b}}$ & Normal & $-3.2831^{* * *}$ & $22.9595 * * *$ & Normal & 0.1556 & $2.6496^{* *}$ \\
\hline Subdivision & Log-normal & $0.1902 * * *$ & $2.9349^{* * *}$ & Log-normal & $0.2034^{* * *}$ & $0.6159 * * *$ \\
\hline Accuracy (unit: \%) & Log-normal & $0.0574^{* * *}$ & $0.2559 * * *$ & Log-normal & $0.0433^{* * *}$ & $0.0646^{* * *}$ \\
\hline $\begin{array}{l}\text { Price (unit: } \\
\text { KRW 100) }\end{array}$ & Normal & $-1.3846^{* * *}$ & $1.0506^{* * *}$ & Normal & $-2.1278^{* * *}$ & $2.2132 * * *$ \\
\hline ASC $^{*}$ Education ${ }^{\mathrm{c}}$ & & & & Normal & $0.1722 *$ & $1.2679^{* * *}$ \\
\hline ASC $^{*}$ Income ${ }^{\mathrm{C}}$ & & & & Normal & $-1.1091^{* * *}$ & $4.9017^{* * *}$ \\
\hline ASC $^{*}$ Gender $^{c}$ & & & & Normal & -0.2828 & $31.6085^{* * *}$ \\
\hline $\begin{array}{l}\text { Number of } \\
\text { observations }\end{array}$ & \multicolumn{6}{|c|}{4000} \\
\hline
\end{tabular}

Notes: ${ }^{a}$ The variables are described in Table $3 .{ }^{b}$ ASC indicates an alternative-specific constant that means a dummy for the respondent's selecting the business-as-usual alternative. ${ }^{c}$ Education, Income, and Gender imply the education level of the interviewee in years, the monthly income the interviewee household, and the gender the interviewee. ${ }^{*}, * *$, and ${ }^{* * *}$ indicate statistical significance at the significance of $10 \%, 5 \%$, and $1 \%$, respectively.

The MWTP estimates for the individual attributes are presented in Table 5. According to the estimation results that do not include covariates, the household MWTP for a one-step Subdivision was USD 0.12, and the household MWTP for a 1\%p improvement in Accuracy was USD 0.04 .

Table 5. Marginal willingness to pay (MWTP) estimates.

\begin{tabular}{cc}
\hline Attributes & MWTP Estimate per Household per Year \\
\hline Improvement of Subdivision & KRW 137 (USD 0.12) \\
Improvement of Accuracy (units: \%p) & KRW 41 (USD 0.04) \\
\hline
\end{tabular}

Note: At the time of the survey, USD 1.0 was approximately equal to 1165 Korean won.

\subsection{Discussion of the Results}

Two cross-product terms for variables related to respondent characteristics and ASC, among the three cross-product terms for variables and ASC, significantly affected the utility. For instance, the coefficient for the cross-product term for the interviewee household income and ASC was statistically significantly estimated as negative. On the other hand, the cross-product term for the interviewee's education level and ASC had a positive impact on the utility.

There are three issues concerning the ADAM improvement in several processes of AD-forecasting information production. First, there is a need to provide more observational information on the source of AD. The numerous observational information is required to evaluate the prediction model being developed/used. However, in the case of AD, international cooperation is essential because the source is not located on the Korean Peninsula. Currently, WMO is operating SDS-WAS (Sand and dust storm-warning advisory and assessment system), and KMA is participating in it. In addition, KMA continues to collaborate with China and Japan to improve AD monitoring and forecasting capabilities. It is known that the source of AD is changing with the passage of time. Therefore, it will be necessary to strengthen cooperation with China and Mongolia, which belong to the source of $\mathrm{AD}$, to identify the exact location of source and to strengthen the observation network.

Second, the accuracy of the weather parameters of the AD source algorithm, wind speed at $10 \mathrm{~m}$, relative humidity at $1.5 \mathrm{~m}$, and surface temperature, should be improved. In order for AD to occur, several weather conditions must be satisfied. If the ground becomes wet due to precipitation, even if the wind blows, the amount of AD generated is small or 
does not affect the Korean Peninsula. It is possible to improve the model by applying the data related to the surface condition to the model when AD occurs.

Third, the accuracy of the wind field should be improved when the AD from the source enters the Korean Peninsula. It is necessary to improve the accuracy of the $850 \mathrm{hPa}$ wind field prediction, which plays the most important role when AD occurs in China and Mongolia and flows to the Korean Peninsula.

When ADAM is enhanced in the above-listed ways, it is possible to provide more accurate, customized, and more detailed AD information. In addition, long-term forecasting information of $\mathrm{AD}$ could be produced. $\mathrm{AD}$ not only affects human health, but also adversely affects several industrial sectors. Long-term forecasting (seasonal forecasting) information on precipitation and temperature is already provided, and it has been used by several industries to reduce damage or maximize benefit. Long-term forecasting information for $\mathrm{AD}$ occurrences can be used to demand forecasting, policy establishment, and strategy changes in various industrial sectors. The economic benefit of the improvement of ADAM was estimated as KRW 41 for a 1\%p improvement in Accuracy and KRW 137 for a one-level subdivision of forecast level per household per year. In 2019, the year the survey was executed, the number of households in Korea was 20,891,348. If the estimated economic benefits are expanded to the entire nation, it is found that a $1 \%$ p improvement in Accuracy produces KRW 857 million (USD 0.84 million) per year and each level of forecast Subdivision creates KRW 2862 million (USD 2.5 million) per year. As such, if long-term $\mathrm{AD}$ prediction becomes possible, it is expected to bring greater benefits not only to the household sector but also to the social/economic sector.

\section{Conclusions}

The AD that has been occurring from the Chinese Loess Plateau and the Gobi Desert is blown by wind and affects the Korean peninsula. Baengnyeongdo is the first area that can observe AD in Korea. According to the KMA, from 2000 to 2020, AD has been observed at Baengnyeongdo for 10.7 days each year on average. Because of the desertification and desiccation due to climate change, $\mathrm{AD}$ has been occurring more often not only in the spring season but also inconsistently throughout the year. At the same time, the AD situation is getting more severe than before. It remains longer and causes bad air quality. In addition, people are more concerned about how their health might be influenced by $\mathrm{AD}$. The negative effects of $\mathrm{AD}$ to some industries and human health is already verified through many precedent studies. To reduce the harmful influence from AD, KMA is providing $\mathrm{AD}$-forecasting information before $\mathrm{AD}$ occurs. AD-forecasting information has been produced with several combined sources-the observed data from the starting point of $\mathrm{AD}$, satellite data, forecasting models, one of which is ADAM, and so on. For better AD-forecasting information, ADAM also has to be improved. NIMS, which is the affiliated organization of KMA, is progressing the development of ADAM.

Estimating the economic value ensuing from conducting R\&D is not easy. In spite of that, the estimation needs to be conducted especially about governmental R\&D. This is because taxpayers' money enters into funds for governmental R\&D. For this purpose, in this study, we tried to assume the economic value of improving ADAM, which is the core element for providing the AD forecasting service. In addition, we analyzed users preferences related to ADAM improvement by using CE approach.

The authors believe that this study yields some important findings for policymakers and researchers. First, these results provide information about when ADAM developers should decide the order of precedence for improving ADAM. For example, the evaluated value of a one-level segmentation in AD warnings is higher than a $1 \%$ p improvement in ADAM accuracy. Second, this research can give us some implications for calculating a budget for improving ADAM. Increasing the budget for improving ADAM an adequate amount can provide value by enabling AD forecasts with higher with segmentation levels and enhancements in accuracy. 
In addition, this article contributes to the literature in terms of a few research perspectives. In this article, the $C E$ technique is utilized to investigate the public preferences for ADAM attributes. Its application was successful, with statistically meaningful estimation results and active participation of the survey respondents. The authors also estimated the MWTP for attributes using the ML model. This estimation has the merit of not assuming quite a restrictive IIA assumption. Moreover, the estimation allows for people's heterogeneous preferences. Thus, it was an appropriate and good strategy to employ the ML model. Furthermore, the model can be estimated with ease.

The variables in this study were decided with consideration for previous studies and the opinions of experts who are involved in ADAM improvement. In other words, the ideas from respondents of the survey were not included as variables. Some similar studies included a prior investigation to determine the optimal variables for unspecified individuals. There was not enough time and budget for a prior investigation to choose better variables. Furthermore, only socioeconomic background, which includes education level, household income, and the gender of the respondents, was contained. Considering more diverse backgrounds of respondents could be a chance to explain specifically the preference of each interviewee. In addition, attitudes toward governmental R\&D or the sensitivity of air pollution, including from $\mathrm{AD}$, could also be added in future works.

Author Contributions: Conceptualization, H.-M.K. and I.-G.K.; methodology, S.-H.Y.; software, H.-M.K. and B.L.; validation, B.L.; formal analysis, I.-G.K.; data curation, H.-M.K.; writing-original draft preparation, H.-M.K. and S.-H.Y.; writing-review and editing, S.-H.Y.; visualization, B.L.; project administration, S.-H.Y.; supervision, I.-G.K. and B.L.; funding acquisition, I.-G.K. All authors have read and agreed to the published version of the manuscript.

Funding: This work was funded by the Korea Meteorological Administration Research and Development Program "Support to Use of Meteorological Information and Value Creation" under grant (KMA2018-00122).

Institutional Review Board Statement: Not applicable.

Data Availability Statement: The data used in this article are not publicly available because they were purchased for a fee. However, the data are available on request from the first or corresponding authors.

Conflicts of Interest: The authors declare no conflict of interest.

\section{References}

1. Kashima, S.; Yorifuji, T.; Bae, S.H.; Honda, Y.; Lim, Y.-H.; Hong, Y.-C. Asian dust effect on cause-specific mortality in five cities across South Korea and Japan. Atmos Environ. 2016, 128, 20-27. [CrossRef]

2. Lee, H.W.; Kim, H.; Honda, Y.; Lim, Y.-H.; Yi, S.M. Effect of Asian dust storms on daily mortality in seven metropolitan cities of Korea. Atmos Environ. 2013, 79, 510-517. [CrossRef]

3. Kwon, H.-J.; Cho, S.-H.; Chun, Y.S.; Lagarde, F.; Pershagen, G. Effects of the Asian Dust Events on Daily Mortality in Seoul Korea. Environ. Res. Sect. A 2002, 90, 1-5. [CrossRef]

4. Lee, H.W.; Jung, J.Y.; Myung, W.J.; Baek, J.H.; Kang, J.M.; Kim, D.K.; Kim, H. Association between dust storm occurrence and risk of suicide: Case-crossover analysis of the Korean national death database. Environ. Int. 2019, 133, 105-146. [CrossRef]

5. Lee, K.-K. The fluctuation patterns of conjunctivitis cases caused by Asian dust storm (ADS): Focused on the ADS density and the accuracy of ADS forecast. Korean Manag. Sci. Rev. 2013, 30, 91-102. [CrossRef]

6. Yamaguchi, N.; Sakotani, A.; Ichijo, T.; Kenzaka, T.; Tani, K.; Baba, T.; Nasu, M. Break down of Asian dust particle on wet surface and their possibilities of cause of respiratory health effects. Biol. Pharm. Bull. 2012, 35, 1187-1190. [CrossRef]

7. Chun, Y.S.; Boo, K.-O.; Kim, J.Y.; Park, S.-U.; Lee, M.H. Synopsis, transport, and physical characteristics of Asian dust in Korea. J. Geophys. Res. 2001, 106, 18461-18469. [CrossRef]

8. Otani, S.; Onishi, K.; Mu, H.; Yokoyama, Y.; Hosoda, T.; Okamoto, M.; Kurozawa, Y. The relationship between skin symptoms and allergic reactions to Asian dust. Int. J. Environ. Res. Public Health 2012, 9, 4606-4614. [CrossRef]

9. Lee, E.-H.; Sohn, B.-J. Recent increasing trend in dust frequency over Mongolia and Inner Mongolia regions and its association with climate and surface condition change. Atmos Environ. 2011, 45, 4611-4616. [CrossRef]

10. Shine, K.P.; Forster, P.M. The effect of human activity on radiative forcing of climate change: A review of recent developments. Glob. Planet Chang. 1999, 20, 205-225. [CrossRef] 
11. Yoo, M.H.; Youn, S.H.; Oh, H.J.; Choi, J.K. Reaction characteristics of phytoplankton before and after the yellow dust event in Taean peninsula and yellow dust impact assessment. J. Korean Soc. Mar. Environ. Saf. 2018, 24, 898-906. [CrossRef]

12. Chung, Y.-S. On the observations of yellow sand (dust storms) in Korea. Atmos Environ. Part A 1992, 26, 2743-2749. [CrossRef]

13. Zhao, T.L.; Gong, S.L.; Zhang, X.Y.; Jaffe, D.A. Asian dust storm influence on north American ambient PM levels: Observational evidence and controlling factors. Atmos Chem. Phys. 2008, 8, 2717-2728. [CrossRef]

14. Kim, H.-J.; Lim, S.-Y.; Yoo, S.-H. The South Korean public's evaluation of the mix of power generation sources: A choice experiment study. Energy Environ. 2019, 31, 1181-1190. [CrossRef]

15. Chen, H.-S.; Chen, C.-W. Economic valuation of Green Island, Taiwan: A choice experiment method. Sustainability 2019, 11, 403. [CrossRef]

16. Lee, H.-C.; Kang, J.-W.; Han, S.-F.; Kim, K.-H. Valuating the Mangyeong river space using a choice experiment. J. Environ. Policy Adm. 2016, 24, 1-24. [CrossRef]

17. Lee, J.-S. The environmental costs of Asian dust damages in Korea: Applying a choice experiment. Environ. Econ. Policy Stud. 2018, 20, 641-654. [CrossRef]

18. Tesfaye, A.; Hansen, J.; Kassie, G.T.; Radeny, M.; Solomon, D. Estimating the economic value of climate services for strengthening resilience of smallholder farmers to climate risks in Ethiopia: A choice experiment approach. Ecol. Econ. 2019, 162, 157-168. [CrossRef]

19. Nguyen, T.C.; Robinson, J.; Kaneko, S.; Komatsu, S. Estimating the value of economic benefits associated with adaptation to climate change in a developing country: A case study of improvements in tropical cyclone warning services. Ecol. Econ. 2013, 86, 117-128. [CrossRef]

20. Lin, H.-I.; Liou, J.-L.; Hsu, S.-H. Economic valuation of public meteorological information services-A case study of agricultural producers in Taiwan. Atmosphere 2019, 10, 753. [CrossRef]

21. Lee, J.-W.; Jang, J.; Ko, K.-K.; Cho, Y. Economic valuation of a new meteorological information service: Conjoint analysis for a pollen forecast system. Weather Clim. Soc. 2014, 6, 495-505. [CrossRef]

22. Park, S.-Y.; Lim, S.-Y.; Yoo, S.-H. The economic value of the National meteorological service in the Korean household sector: A contingent valuation study. Sustainability 2016, 8, 834. [CrossRef]

23. Desaigues, D.; Ami, D.; Bartczak, A.; Baun-Kohlova, M.; Chilton, S.; Czajkowski, M.; Farreras, V.; Hunt, A.; Hutchison, M.; Jeanrenaud, C.; et al. Economic valuation of air pollution mortality: A 9-country contingent valuation survey of value of a life year (VOLY). Ecol. Indic. 2011, 11, 902-910. [CrossRef]

24. Donfouet, H.P.P.; Cook, J.; Jeanty, P.W. The economic value of improved air quality in urban Africa: A contingent valuation survey in Douala, Cameroon. Environ. Dev. Econ. 2014, 20, 630-639. [CrossRef]

25. Louviere, J.J. Conjoint analysis modelling of stated preferences: A review of theory, methods, recent developments and external validity. J. Transp. Econ. Policy 1988, 22, 93-119.

26. Adamowicz, W.; Louviere, J.; Williams, M. Combining revealed and stated preference methods for valuing environmental amenities. J. Environ. Econ. Manag. 1994, 26, 271-292. [CrossRef]

27. Bateman, I.J.; Carson, R.T.; Day, B.l.; Haneman, M.; Hanley, N.; Hett, T.1.; Jones-Lee, M.; Loomes, G.; Mourato, S.; Özdemirog ${ }^{-}$lu, E.; et al. Economic Valuation with Stated Preference Techniques: A Manual; Edward Elgar Publishing Ltd.: Cheltenham, UK, 2002.

28. Kim, J.-H.; Kim, H.-J.; Yoo, S.-H. Willingness to pay for fuel-cell electric vehicles in South Korea. Energy 2019, 174, 497-502. [CrossRef]

29. Champ, P.A.; Boyle, K.J.; Brown, T.C. A Primer on Nonmarket Valuation; Springer: Basel, Switzerland, 2003.

30. Rollins, K.S.; Shaykewich, J. Using willingness-to-pay to assess the economic value of weather forecasts for multiple commercial sectors. Meteorol. Appl. 2003, 10,31-38. [CrossRef]

31. Louviere, J.J.; Flynn, T.N.; Carson, R.T. Discrete choice experiments are not conjoint analysis. J. Choice Model. 2010, 3, 57-72. [CrossRef]

32. Adamowicz, W.; Boxall, P.; Williams, M.; Louviere, J. Stated preference approaches for measuring passive use values: Choice experiments and contingent valuation. Am. J. Agric. Econ. 1998, 80, 64-75. [CrossRef]

33. Diener Alan, A.; Muller, R.; Andrew, R.A.L. Willingness-to-Pay for Improved Air Quality in Hamilton-Wentworth: A Choice Experiment; Working Paper; Department of Economics, McMaster University Hamilton: Hamilton, ON, Canada, 1988; pp. 421-429.

34. Hanley, H.; Wright, R.E.; Adamowicz, V. Using choice experiments to value the environment. Environ. Resour. Econ. 1998, 11, 413-428. [CrossRef]

35. Morrison, M.; Bennet, J.; Blamey, R.; Louviere, J. Choice modeling and tests of benefit transfer. Am. J. Agric. Econ. 2002, 84, 161-170. [CrossRef]

36. Yoo, S.-H.; Kwak, S.J.; Lee, J.S. Measuring the environmental costs of air pollution impacts in Seoul: A conjoint analysis. J. Korean Reg. Sci. Assoc. 2003, 19, 1-17.

37. Jin, S.-J.; Lim, S.-Y.; Park, S.-H.; Yoo, S.-H. Measuring the scientific benefits from the deep-sea human-operated vehicle project: A choice experiment study. Ocean Polar Res. 2014, 36, 277-288. [CrossRef]

38. Shoyama, K.; Managi, S.; Yamagata, Y. Public preferences for biodiversity conservation and climate-change mitigation: A choice experiment using ecosystem services indicators. Land Use Policy 2013, 34, 282-293. [CrossRef]

39. Train, K.E. Discrete Choice Methods with Simulation, 2nd ed.; Cambridge University Press: Cambridge, UK, 2009. 